\title{
Clinical Outcomes of Direct Oral Anticoagulants and Warfarin in Japanese Patients with Atrial Fibrillation Aged $\geq 85$ Years: A Single-Center Observational Study
}

\author{
Miyoko Naganuma $^{1,2} \cdot$ Tsuyoshi Shiga $^{2,3}$ (D) Nobuhisa Hagiwara ${ }^{2}$
}

Published online: 10 August 2020

(c) The Author(s) 2020

\begin{abstract}
Background Increasing age is associated with an increase in stroke in patients with nonvalvular atrial fibrillation (NVAF). Elderly patients have several comorbidities and increased bleeding risk.

Objective The aim of this study was to evaluate the clinical outcomes of Japanese patients with NVAF aged $\geq 85$ years who were treated with direct oral anticoagulants (DOACs) or warfarin.

Methods We retrospectively studied the records of 358 patients with NVAF aged $\geq 85$ years who had taken DOACs or warfarin between 2014 and 2018. The primary endpoints were the first occurrences of thromboembolic and bleeding events and death. The secondary endpoint was the discontinuation of oral anticoagulation (OAC) therapy.

Results During a median follow-up period of 17 months, 24 patients died. The incidence (per 100 patient-years [PY]) of thromboembolic events was 1.8 in patients treated with DOACs and 2.2 in those treated with warfarin (adjusted subdistribution hazard ratio [SHR] 0.69; 95\% confidence interval [CI] 0.23-2.12 in a competing model), and the incidence of major bleeding events was 3.1 and 4.2 in patients treated with DOACs and warfarin, respectively (adjusted SHR 0.95; 95\% CI 0.32-2.86). The most common cause of bleeding events was gastrointestinal bleeding. A total of 33 patients permanently discontinued OAC therapy, at a median age of 89 years and with no differences between DOACs and warfarin. The most common reason for discontinuing OAC therapy was bleeding events.

Conclusion Our results revealed that the incidences of thromboembolism and major bleeding among patients with NVAF aged $\geq 85$ years were similar for those treated with DOACs and those treated with warfarin. Approximately $10 \%$ of patients permanently discontinued OAC therapy.
\end{abstract}

\section{Introduction}

Atrial fibrillation (AF) is a clinically encountered arrhythmia and an important risk factor for stroke and impaired quality of life [1-5]. The incidence of AF increases with age [1-3],

\section{Electronic supplementary material The online version of this} article (https://doi.org/10.1007/s40801-020-00209-4) contains supplementary material, which is available to authorized users.

Tsuyoshi Shiga

shiga@jikei.ac.jp

1 Department of Pharmacy, International University of Health and Welfare Atami Hospital, Atami, Japan

2 Department of Cardiology, Tokyo Women's Medical University, Tokyo, Japan

3 Department of Clinical Pharmacology and Therapeutics, The Jikei University School of Medicine, 3-25-8 Nishi-shinbashi, Minato-ku, Tokyo 105-8461, Japan

\section{Key Points}

The incidences of thromboembolism and major bleeding were not different between Japanese atrial fibrillation patients aged $\geq 85$ years taking DOACs and those taking warfarin. The most common cause of bleeding events was gastrointestinal bleeding and subsequent subdural hemorrhage.

During a median follow-up period of 17 months, 24 (7\%) of 358 patients died. More than half of the deaths were attributed to noncardiovascular causes.

Approximately $10 \%$ of very elderly patients permanently discontinued anticoagulation treatment. The common reasons were bleeding events and concomitant diseases such as malignancy and infections. 
and increasing age is associated with an increase in stroke in patients with AF [7-9]. Oral anticoagulation (OAC) is a potent treatment to prevent stroke and systemic embolism in patients with nonvalvular AF (NVAF) and is associated with an increased risk of bleeding in patients with advanced age. In particular, major bleeding events impair quality of life and physical activity and are associated with earlier mortality in very old patients [10].

Previous large cohort and randomized controlled studies have shown that warfarin therapy within a recommended prothrombin time-international normalized ratio (PT-INR) range (2.0-3.0) was effective, even in elderly patients with NVAF, without an increased risk of bleeding compared with the risks associated with other antithrombotic therapies [11, 12]. In the era of direct oral anticoagulants (DOACs), recent studies suggested the benefit of OACs and the usefulness of DOACs over warfarin, even for very elderly patients with NVAF [13-17]. Asian patients, including Japanese patients, have a higher risk of intracranial hemorrhage than white patients $[18,19]$. Very elderly Japanese patients have a small body size and reduced renal function. However, in real-world settings, outcomes such as thromboembolic and bleeding events and death in very elderly Japanese patients treated with OAC therapy or those who discontinue OAC therapy are not clear because patients with advanced age have several comorbidities and increased bleeding risk [15, 20,21]. The aim of this study was to evaluate the clinical outcomes of elderly Japanese patients with NVAF aged $\geq 85$ years who were treated with DOACs or warfarin.

\section{Methods}

\subsection{Patients}

We conducted a retrospective cohort study of patients with NVAF aged $\geq 85$ years who had taken oral anticoagulants between January 2014 and October 2018 at the Tokyo Women's Medical University Hospital. The study included consecutive patients with NVAF who had already taken DOACs or warfarin and were aged $\geq 85$ years between January 2014 and June 2018 , patients aged $\geq 85$ years who recently started DOACs or warfarin between January 2014 and June 2018, and patients aged $\geq 85$ years who had changed their OAC drug between January 2014 and June 2018 (the date the drug was first prescribed was defined as the start of follow-up). If the OAC drug was changed in the same patient between January 2014 and October 2018, the patient was counted as a user of both drugs and followed only for the period in which they received the drug.

To identify patients who were prescribed DOACs or warfarin, we first searched the automated prescription databases. Then, we confirmed each patient's age and diagnosis of AF by checking their medical records. Patients with valvular heart disease or concurrent hyperthyroidism were excluded. Valvular heart disease was defined as moderate or severe mitral stenosis and mild rheumatic mitral stenosis based on angiographic, hemodynamic, or echocardiographic results or a history of mechanical valve or bioprosthetic valve replacement but not valve repair [22]. Patients who transiently used $\mathrm{OAC}$ drugs for cardioversion or catheter ablation were also excluded.

This study was approved by the institutional review board of the Tokyo Women's Medical University (approval number 2887-R2).

\subsection{Clinical Characteristics}

Data on patient age, sex, traditional risk factors (such as hypertension, diabetes mellitus, and heart failure [HF]), underlying diseases, and concomitant medications were obtained from medical records and laboratory data. Creatinine clearance $(\mathrm{CrCl})$ was calculated using the Cockcroft-Gault formula [23]. Hypertension was defined as systolic blood pressure $\geq 140 \mathrm{mmHg}$, diastolic blood pressure $\geq 90 \mathrm{mmHg}$, or a history of treatment for hypertension. Diabetes mellitus previously diagnosed by a physician was indicated by treatment with hypoglycemic agents or by poor glycemic control (defined as glycated hemoglobin [HbA1c] $\geq 6.5 \%)$. Coronary artery disease was defined based on positive stress test results, coronary angiography demonstrating at least $75 \%$ stenosis, or coronary spastic angina documented by an acetylcholine provocation test, a history of prior myocardial infarction, or a history of revascularization procedures. HF was defined according to the American College of Cardiology/American Heart Association criteria [24]; the patients in our study were classed as stage $\mathrm{C}$ (current or prior symptoms of HF) or stage $\mathrm{D}$ (refractory HF).

Stroke risk was measured using the $\mathrm{CHADS}_{2}$ score (congestive HF, hypertension, age $\geq 75$, diabetes, stroke [doubled]) and the $\mathrm{CHA}_{2} \mathrm{DS}_{2}$-VASc score (congestive HF/left ventricular dysfunction, hypertension, age $\geq 75$ [doubled], diabetes, stroke [doubled] — vascular disease, age 65-74, and sex category [female]) [25]. Bleeding risk was also obtained using the HAS-BLED score (hypertension, abnormal renal/ liver function, stroke, bleeding history or predisposition, labile INR, elderly [ $\geq 65$ years], and concomitant drugs/ alcohol) [25].

\subsection{Follow-Up}

Follow-up data were obtained at routine or additional visits in our institution. The patients were monitored until the end of the follow-up period (31 October 2018), until they stopped attending follow-up visits, or until they died. 
Information concerning deceased patients was obtained from the patients' medical records, family members, general practitioners, and the hospitals to which they had been admitted. For patients receiving warfarin, we also collected PT-INR data.

\subsection{Outcomes}

The primary endpoints were the first occurrences of thromboembolic and bleeding events and death during OAC therapy. The secondary endpoint was the discontinuation of OAC therapy.

The occurrence of thromboembolic and bleeding events was validated via a review of the medical records by two investigators (MN and TS). Thromboembolic events included fatal or nonfatal ischemic strokes, transient ischemic attack (TIA), or other systemic embolisms. Ischemic stroke was defined as the sudden onset of a new focal neurological deficit that lasted more than $24 \mathrm{~h}$ and could not be explained by other causes. Patients were diagnosed with TIA when the neurological deficit lasted less than $24 \mathrm{~h}$. Computed tomography or magnetic resonance imaging was performed on all patients. Other systemic embolisms were diagnosed using computed tomography, angiography, or thrombectomy, and their diagnosis was based on the absence of underlying atherosclerosis in the affected artery. Major bleeding was defined as intracranial hemorrhage observed by imaging; gastrointestinal hemorrhage or another severe hemorrhage that was fatal or required endoscopic hemostasis, surgical intervention, or hospital admission; and bleeding that caused a decrease in hemoglobin level of $\geq 2 \mathrm{~g} /$ $\mathrm{dL}$ or that required a blood transfusion. Death due to HF was defined as decompensated HF or treatment-resistant HF in the absence of another cause. Sudden death was defined as a nontraumatic, unexpected death occurring within $1 \mathrm{~h}$ of the onset of symptoms or within $24 \mathrm{~h}$ after the patient was last seen alive if the death was not witnessed. The cause of death was categorized as "undetermined" if evidence was insufficient to determine a certain cause, including "dying of old age."

The discontinuation of OAC therapy was defined as the discontinuation of the prescribed anticoagulant drug and a physician's mention of OAC discontinuation in the medical record. All OAC discontinuations in the medical records were reviewed and reasons for discontinuation obtained. Patients who changed to other anticoagulant drugs were not categorized as having discontinued OAC therapy. Patients who interrupted OAC therapy for specific reasons, such as surgery, and restarted OAC therapy during the observation period were defined as having discontinued OAC therapy, and only the period for which they used the OAC drugs was adopted as the observation period.

\subsection{Statistical Analysis}

Summary data are presented as numbers and as medians with ranges for continuous and categorical data, respectively. The baseline clinical data for patients treated with DOACs and those treated with warfarin were compared using the Mann-Whitney $U$ test. Categorical variables were analyzed with the Chi-squared test. Time in therapeutic range (TTR) was calculated using the Rosendaal linear interpolation method [26], a linear interpolation of consecutive PT-INR values that calculates the percentage of time that the PT-INR is below, within, or above the therapeutic range (1.6-2.6), which is based on the target PT-INR for low intensity in Japanese clinical practice [22].

We calculated the incidence rates (per 100 patient-years $[\mathrm{PY}]$ ), and their 95\% confidence interval (CIs), of thromboembolic and major bleeding events and death. The hazard of thromboembolic and major bleeding events was assessed using the Fine and Gray competing risk regression model [27]. In the model, all-cause death was included as a competing risk because of the high mortality rate in elderly patients. The hazard of death was assessed using the Cox regression model. These models were adjusted for age, sex, body weight, $\mathrm{CrCl}$, and $\mathrm{CHADS}_{2}$ score. We also assessed the relationship between major bleeding events and the following risk factors for bleeding: hypertension, renal failure (defined as $\mathrm{CrCl}<30 \mathrm{~mL} / \mathrm{min}$ ), prior stroke, history of major bleeding, antiplatelet/nonsteroidal anti-inflammatory drug (NSAID) use, and HAS-BLED score $\geq 3$. Death was treated as a competing risk using the Fine and Gray competing risk regression model for univariate and multivariate analyses. The forward stepwise method was used for the multivariate analyses with entry or removal on the basis of $p$ values set at 0.10. A subdistribution hazard ratio (SHR), which is interpreted as the HR for the event of interest in the presence of competing events (death), was estimated from this model. The SHRs of thromboembolic and major bleeding events and the HR of death were also analyzed adjusted for age, sex, body weight, $\mathrm{CrCl}$, and $\mathrm{CHADS}_{2}$ score. The cumulative rates of the discontinuation of OAC therapy were estimated using the cumulative incidence method. Differences in discontinuation rates between patients treated with DOACs and those treated with warfarin were compared using Gray's test. A $p$-value $<0.05$ was considered significant. All statistical analyses were performed with EZR (Saitama Medical Center, Jichi Medical University, Saitama, Japan), which is a graphical user interface of R (The R Foundation for Statistical Computing, Vienna, Austria, version 3.6.1) [28]. More precisely, it is a modified version (version 1.41) of R commander (version 2.6-1) designed to add statistical functions frequently used in biostatistics. 


\section{Results}

\subsection{Patient Characteristics}

The patients' baseline characteristics are shown in Table 1 . The median age at the start of follow-up and the proportion of females was higher in the DOAC group than in the warfarin group. $\mathrm{CrCl}$ was slightly higher in patients treated with DOACs than in those treated with warfarin, and the proportion of renal failure $(\mathrm{CrCl}<30 \mathrm{~mL} / \mathrm{min})$ was lower in patients treated with DOACs than in those treated with warfarin. Patients treated with warfarin but not DOACs included two patients with hemodialysis. The distribution of the $\mathrm{CHADS}_{2}$ or $\mathrm{CHA}_{2} \mathrm{DS}_{2}$-VASc scores did not differ between the DOAC and warfarin treatment groups. More patients treated with warfarin were digoxin users. All digoxin users started digoxin before the age of 85 years, and no incidence of digitalis intoxication was observed during the follow-up period.

Regarding the daily dose of DOACs, the frequency of low-dose users was higher in this population compared with the younger AF population. In this study, 90 (25\%) of 358 patients were new OAC users (incident users), and most of them (77 patients) were newly introduced to DOACs. On the other hand, 178 (66\%) of 268 prevalent users continued warfarin, whereas the remainder continued DOAC treatment, which was newly started, or switched from warfarin before the age of 85 years. The mean TTR during the maintenance phases of warfarin therapy was $64 \%$. Three patients were lost to follow-up.

\subsection{Thromboembolic and Bleeding Events and Death}

During the median (range) follow-up period of 17 (1-58) months, 24 (7\%) patients died, 12 (3\%) experienced thromboembolic events, and 22 (6\%) experienced major bleeding events during OAC therapy. The causes of thromboembolic and major bleeding events and death are listed in Table 2 . During the follow-up period, 25 patients switched from warfarin to DOACs, and five patients switched from DOACs to warfarin. There were no occurrences of thromboembolic or major bleeding events associated with switching.

The incidence of thromboembolic events was 1.8 and 2.2/100 PY and the incidence of major bleeding events was 3.1 and 4.2/100 PY with DOACs and warfarin, respectively. There were no differences in the adjusted SHRs (from the Fine-Gray competing risk model) of thromboembolic and major bleeding events between patients treated with DOACs and patients treated with warfarin (Table 3 ). Ischemic stroke occurred in half of the patients taking warfarin under the therapeutic range of PT-INR and in the other half with the
Table 1 Patient baseline characteristics

\begin{tabular}{|c|c|c|c|}
\hline Characteristic & DOACs & Warfarin & $p$ value \\
\hline Number & 167 & 191 & \\
\hline Age (years) & $87(85-95)$ & $85(85-96)$ & 0.02 \\
\hline Female & $83(50)$ & $68(36)$ & $<0.01$ \\
\hline Patient-years & 228 & 356 & \\
\hline Body weight (kg) & $53(28-91)$ & $58(30-85)$ & $<0.01$ \\
\hline $\mathrm{CrCl}(\mathrm{mL} / \mathrm{min})$ & $38(14-79)$ & $36(9-73)$ & 0.02 \\
\hline $\mathrm{CcCl}<30 \mathrm{~mL} / \mathrm{min}$ & $30(18)$ & $67(35)$ & $<0.01$ \\
\hline Permanent AF & $50(30)$ & $112(59)$ & $<0.01$ \\
\hline Heart failure & $46(28)$ & $69(36)$ & 0.08 \\
\hline Hypertension & $131(78)$ & $144(75)$ & 0.50 \\
\hline Diabetes mellitus & $54(32)$ & $64(34)$ & 0.81 \\
\hline Previous TIA/stroke & $46(28)$ & $42(22)$ & 0.22 \\
\hline Coronary artery disease & $56(34)$ & $53(28)$ & 0.10 \\
\hline \multicolumn{4}{|l|}{$\mathrm{CHADS}_{2}$ score } \\
\hline Median & $3(1-6)$ & $3(1-6)$ & 0.75 \\
\hline 1 & $13(8)$ & $18(9)$ & \\
\hline 2 & $54(32)$ & $65(34)$ & \\
\hline 3 & $48(29)$ & $48(25)$ & \\
\hline 4 & $37(22)$ & $45(24)$ & \\
\hline 5 & $13(8)$ & $10(5)$ & \\
\hline 6 & $2(1)$ & $5(3)$ & \\
\hline \multicolumn{4}{|l|}{$\mathrm{CHA}_{2} \mathrm{DS}_{2-}$ VASc score } \\
\hline Median & $4(2-9)$ & $4(2-9)$ & 0.40 \\
\hline 2 & $3(2)$ & $10(5)$ & \\
\hline 3 & $23(14)$ & $36(19)$ & \\
\hline 4 & $49(29)$ & $50(26)$ & \\
\hline 5 & $46(28)$ & $42(22)$ & \\
\hline 6 & $31(19)$ & $37(19)$ & \\
\hline 7 & $12(7)$ & $10(5)$ & \\
\hline 8 & $2(1)$ & $5(3)$ & \\
\hline 9 & $1(1)$ & $1(1)$ & \\
\hline \multicolumn{4}{|l|}{ HAS-BLED bleeding risk score } \\
\hline Median & $2(1-5)$ & $3(1-5)$ & 0.47 \\
\hline 1 & $16(10)$ & $21(11)$ & \\
\hline 2 & $76(46)$ & $74(39)$ & \\
\hline 3 & $58(35)$ & $75(39)$ & \\
\hline 4 & $16(10)$ & $15(8)$ & \\
\hline 5 & $1(1)$ & $6(3)$ & \\
\hline \multicolumn{4}{|l|}{ Concomitant medications } \\
\hline Aspirin & $30(18)$ & $32(17)$ & 0.76 \\
\hline Other antiplatelets & $24(8)$ & $28(15)$ & 0.94 \\
\hline ACE inhibitors/ARBs & $91(54)$ & $112(59)$ & 0.99 \\
\hline Beta-blockers & $89(53)$ & $92(48)$ & 0.33 \\
\hline Calcium channel blockers & $98(59)$ & $93(49)$ & 0.06 \\
\hline Digoxin & $17(13)$ & $55(29)$ & $<0.01$ \\
\hline Statin & $67(40)$ & $70(37)$ & 0.50 \\
\hline Amiodarone & $6(4)$ & $16(8)$ & 0.11 \\
\hline Other antiarrhythmic drugs & $13(8)$ & $21(11)$ & 0.21 \\
\hline NSAIDs & $8(5)$ & $14(7)$ & 0.32 \\
\hline
\end{tabular}


Table 1 (continued)

\begin{tabular}{llll}
\hline Characteristic & DOACs & Warfarin & $p$ value \\
\hline Dabigatran $220 \mathrm{mg} / 300 \mathrm{mg}$ & $20 / 0$ & & \\
Rivaroxaban $10 \mathrm{mg} / 15 \mathrm{mg}$ & $47 / 1$ & & \\
Apixaban $5 \mathrm{mg} / 10 \mathrm{mg}$ & $54 / 1$ & \\
Edoxaban $15 \mathrm{mg} / 30 \mathrm{mg} / 60 \mathrm{mg}$ & $5 / 37 / 2$ & \\
\hline
\end{tabular}

Values are $n(\%)$ or median (range) unless otherwise indicated

$A C E$ angiotensin-converting enzyme, $A F$ atrial fibrillation, $A R B$ angiotensin II receptor blocker, $C H A D S_{2}$ cardiac failure, hypertension, age $\geq 75$ years, diabetes, previous stroke or TIA (doubled), $\mathrm{CHA}_{2} \mathrm{DS}_{2}-V A S c$ congestive heart failure/LV dysfunction, hypertension, age $\geq 75$ years (doubled), diabetes, previous stroke/TIA/thromboembolism (doubled), vascular disease, age 65-74 years, female sex, $\mathrm{CrCl}$ creatinine clearance, DOACs direct oral anticoagulants, HAS-BLED hypertension, abnormal renal/liver function, stroke, bleeding history or predisposition, labile prothrombin time-international normalized ratio, elderly ( $\geq 65$ years), and concomitant drugs/ alcohol, NSAIDs non-steroidal anti-inflammatory drugs, TIA transient ischemic attack

target therapeutic range (Table S1). Major bleeding events were mostly caused by gastrointestinal bleeding, including diverticular bleeding of the colon, followed by subdural hemorrhage and traumatic hemorrhage, such as hemorrhage caused by falls in elderly individuals (Table 2, Table S2). Multivariate competing risk analysis showed that a history of major bleeding and renal failure $(\mathrm{CrCl}<30 \mathrm{~mL} / \mathrm{min})$ were significantly associated with bleeding risk (Table 4).

The incidence of total death was 2.6 and 5.3/100 PY with DOACs and warfarin, respectively, but there was no difference in the HR between the two groups. Noncardiovascular causes accounted for more than half of all deaths, and HF was the most common cause of cardiovascular death (Table 2).

\subsection{Discontinuation of Oral Anticoagulant (OAC) Therapy}

During the follow-up period, approximately $10 \%$ of very elderly patients permanently discontinued OAC therapy, at a median age of 89 years (Table 5). Information on the cumulative discontinuation of OAC therapy is shown in Fig. 1. The cumulative rates of discontinuation of OAC therapy at 24 months after the start of follow-up were 10.3 and $11.8 \%$ with DOACs and warfarin, respectively. There were no differences in the discontinuation of OAC therapy between patients treated with DOACs and those treated with warfarin.

Bleeding events were the most common reason for discontinuing OAC therapy, and poor control of PT-INR in warfarin users and nonadherence were also important causes. In particular, concomitant diseases, including malignancies and
Table 2 Causes of thromboembolism, major bleeding, and death

\begin{tabular}{llc}
\hline Cause & DOACs & Warfarin \\
\hline Thromboembolism & 4 & 8 \\
Fatal ischemic stroke & 0 & 2 \\
Non-fatal ischemic stroke & 3 & 6 \\
TIA & 0 & 0 \\
Systemic embolism & 1 & 0 \\
Major bleeding & 7 & 15 \\
Intracranial hemorrhage & 2 & 2 \\
Gastrointestinal bleeding & 5 & 10 \\
Others & 0 & 3 \\
Death & 6 & 18 \\
Stroke & 0 & 2 \\
Sudden death & 1 & 1 \\
Heart failure & 0 & 5 \\
Infections & 2 & 3 \\
Renal failure & 0 & 1 \\
Other non-cardiac causes & 0 & 1 \\
Unknown/undetermined & 3 & 5 \\
\hline
\end{tabular}

Values are $n$

$D O A C$ direct oral anticoagulant, TIA transient ischemic attack

pneumonia, were the next most common causes among this population (Table 5).

Among 33 patients who permanently discontinued OAC therapy, 13 patients died and six experienced ischemic stroke after discontinuation. The causes of death were due to concomitant diseases, not thromboembolism (Table 6).

\section{Discussion}

Our study of patients with NVAF aged $\geq 85$ years who took DOACs or warfarin revealed the following findings. (1) The proportion of renal failure $(\mathrm{CrCl}<30 \mathrm{~mL} / \mathrm{min})$ was lower in patients treated with DOACs than in those treated with warfarin. (2) The incidences of thromboembolism and major bleeding were not different between those treated with DOACs and those treated with warfarin. (3) Major bleeding events were caused by gastrointestinal bleeding, subdural hemorrhage, and traumatic causes of hemorrhage such as falls. (4) Approximately $10 \%$ of very elderly patients permanently discontinued OAC therapy, but no differences were observed between patients treated with DOACs and those treated with warfarin. (5) Bleeding events were the most common reason for discontinuing OAC therapy, and concomitant diseases such as malignancy and infections were the next common causes. 
Table 3 Incidences of thromboembolism and major bleeding during oral anticoagulation

\begin{tabular}{|c|c|c|c|c|c|c|}
\hline \multirow[t]{2}{*}{ Event } & \multicolumn{2}{|c|}{ Incident rate per $100 \mathrm{PY}$} & \multirow[t]{2}{*}{ SHR/HR* } & \multirow[t]{2}{*}{$p$ value } & \multirow[t]{2}{*}{ Adjusted SHR/HR ${ }^{\dagger}, *$} & \multirow[t]{2}{*}{$p$ value } \\
\hline & DOACs & Warfarin & & & & \\
\hline Thromboembolism & $1.8(0.1-3.5)$ & $2.2(0.7-3.8)$ & $0.75(0.23-2.47)$ & 0.63 & $0.69(0.23-2.12)$ & 0.52 \\
\hline Major bleeding & $3.1(0.8-5.3)$ & $4.2(2.1-6.3)$ & $0.83(0.31-2.17)$ & 0.70 & $0.95(0.32-2.86)$ & 0.93 \\
\hline Death & $2.6(1.2-5.8)$ & $5.3(3.4-8.3)$ & $0.53(0.21-1.35)$ & 0.18 & $0.78(0.28-2.18)$ & 0.64 \\
\hline
\end{tabular}

Values in parentheses are $95 \%$ confidence intervals

$C H A D S_{2}$ cardiac failure, hypertension, age $\geq 75$ years, diabetes, previous stroke or TIA (doubled), DOACs direct oral anticoagulants, HR hazard ration, $P Y$ patient-years, $S H R$ subdistribution hazard ratio

*Compared with patients taking warfarin as the reference

${ }^{\dagger}$ Adjusted for age, sex, body weight, creatinine clearance, $\mathrm{CHADS}_{2}$ score (cardiac failure, hypertension, age $\geq 75$ years, diabetes mellitus, previous stroke or transient ischemic attack)

Table 4 Bleeding risk in very elderly nonvalvular atrial fibrillation patients receiving oral anticoagulation treatment

\begin{tabular}{|c|c|c|c|c|}
\hline \multirow[t]{2}{*}{ Risk } & \multicolumn{2}{|l|}{ Univariate } & \multicolumn{2}{|l|}{ Multivariate } \\
\hline & SHR & $p$ value & SHR & $p$ value \\
\hline Hypertension & $0.58(0.24-1.37)$ & 0.21 & & \\
\hline $\mathrm{CrCl}<30 \mathrm{~mL} / \mathrm{min}$ & $3.02(1.25-7.29)$ & 0.01 & $3.05(1.24-7.49)$ & 0.02 \\
\hline Prior stroke & $1.22(0.44-3.36)$ & 0.70 & & \\
\hline History of major bleeding & $3.40(0.86-13.40)$ & 0.08 & 3.47 (1.19-10.06) & 0.02 \\
\hline Antiplatelets/NSAIDs & $0.64(0.17-2.37)$ & 0.50 & & \\
\hline HAS-BLED score $\geq 3$ & $1.00(0.28-3.06)$ & 0.99 & & \\
\hline
\end{tabular}

Values in parentheses are $95 \%$ confidence intervals

$\mathrm{CrCl}$ creatinine clearance, $\mathrm{HAS}$ - $\mathrm{BLED}$ hypertension, abnormal renal/liver function, stroke, bleeding history or predisposition, labile prothrombin time-international normalized ratio, elderly ( $\geq 65$ years), and concomitant drugs/alcohol, NSAID non-steroidal anti-inflammatory drug, SHR subdistribution hazard ratio
Table 5 Incidence and reasons for oral anticoagulation discontinuation

\begin{tabular}{llll}
\hline Event & $\begin{array}{l}\text { DOACs } \\
(n=167)\end{array}$ & $\begin{array}{l}\text { Warfarin } \\
(n=191)\end{array}$ & $p$ value \\
\hline $\begin{array}{l}\text { Discontinuation } \\
\begin{array}{l}\text { Median (range) age at discon- } \\
\text { tinuation, years }\end{array}\end{array}$ & $89(86-93)$ & $22(12)$ & $0.92^{*}$ \\
$\begin{array}{l}\text { Reasons for discontinuation } \\
\text { Bleeding }\end{array}$ & 3 & & 0.32 \\
Maintenance of sinus rhythm & 3 & 1 & \\
$\begin{array}{l}\text { Poor control of PT-INR } \\
\text { Non-adherence }\end{array}$ & - & 3 & \\
Concomitant disease & 2 & 3 & \\
Malignancy & 2 & 3 & \\
Acute illness & 1 & 3 & \\
\hline
\end{tabular}

Values are $n(\%)$ or median (range)

DOACs direct oral anticoagulants, $P T$-INR prothrombin time-international normalized ratio

*Gray's test

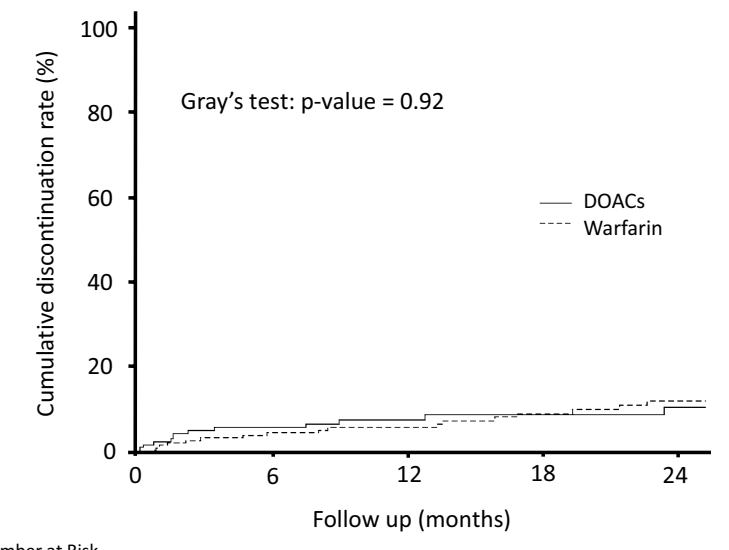

$\begin{array}{llrrrr}\text { Number at Risk } & & & & & \\ \text { DOACs } & 167 & 116 & 89 & 69 & 45 \\ \text { Warfarin } & 191 & 152 & 121 & 101 & 78\end{array}$

Fig. 1 Cumulative discontinuation rates of anticoagulation therapy in Japanese patients with nonvalvular atrial fibrillation aged $\geq 85$ years. DOACs direct oral anticoagulants 
Table 6 Outcomes after discontinuation of oral anticoagulation

\begin{tabular}{llll}
\hline Event & $\begin{array}{l}\text { DOACs } \\
(n=11)\end{array}$ & $\begin{array}{l}\text { Warfarin } \\
(n=22)\end{array}$ & $p$ value \\
\hline Death & 4 & 9 & 0.80 \\
Causes of death & & & \\
$\quad$ Malignancies & 2 & 4 & \\
$\quad$ Infections & 2 & 2 & \\
$\quad$ Sudden death & 0 & 1 & \\
$\quad$ Rupture of aortic aneurysm & 0 & 1 & \\
$\quad$ Undetermined & 0 & 1 & 0.34 \\
$\quad$ Thromboembolism & & & \\
$\quad$ Ischemic stroke & 1 & 5 & \\
\hline
\end{tabular}

Values are $n$

DOACs direct oral anticoagulants

\subsection{Patient Characteristics and the Selection of OAC Drugs}

Subjects in our study had a median (mean) $\mathrm{CHADS}_{2}$ score of 3 (2.9) and a median (mean) $\mathrm{CHA}_{2} \mathrm{DS}_{2}$-VASc score of 4 (4.7). The distributions of the $\mathrm{CHADS}_{2}$ and $\mathrm{CHA}_{2} \mathrm{DS}_{2}$-VASc scores were similar to those of patients aged $\geq 85$ years in a recent large Japanese registry study (ANAFIE) [29]. The median $\mathrm{CrCl}$ was $37 \mathrm{~mL} / \mathrm{min}$, and the proportion of participants with $\mathrm{CrCl}<30 \mathrm{~mL} / \mathrm{min}$ was $27 \%$ in all our patients, which was comparable to the rate among patients aged $\geq 85$ years in the ANAFIE study [29]. The median $\mathrm{CrCl}$ was higher and the proportion of renal failure $(\mathrm{CrCl}<30 \mathrm{~mL} / \mathrm{min})$ was lower in patients treated with DOACs than in those treated with warfarin. This finding might be related to drug choices related to renal function because DOACs are mainly or partially eliminated by the kidneys so have limited use in patients with impaired renal function. In our patients aged $\geq 85$ years, over half received warfarin, and-following apixaban-renal excretion was lowest among those treated with DOACs.

In our patients, the TTR of PT-INR was low, and the majority received a low dose of DOACs, with some of these patients receiving an underdose of DOACs. Recent cohort studies in Japan reported underdosing in approximately $30 \%$ of warfarin users, inappropriately low dosing in $20-30 \%$ of DOAC users, and increased off-label underdosing of DOACs [30, 31]. Japanese physicians tend to prescribe anticoagulants at a lower intensity than physicians in other countries, especially in elderly patients, to avoid bleeding events, and our results might reflect this prescribing behavior.

\subsection{Thromboembolic and Bleeding Events}

Our results showed that the annual rates of ischemic stroke or systemic embolism in patients with NVAF aged $\geq 85$ years were 1.8 and 2.2/100 PY with DOACs and warfarin, respectively. A retrospective analysis from a US database study (ARISTOPHANES) showed that the annual rates of ischemic stroke or systemic embolism in patients with NVAF aged $\geq 80$ years (mean $\mathrm{CHA}_{2} \mathrm{DS}_{2}$-VASc score 4.7-4.8) were 1.4-1.6 and 2.0-2.1/100 PY with DOACs and warfarin, respectively [17]. A subanalysis of a European registry study (PREFER in AF) showed an annual rate of thromboembolic events of 4.3/100 PY in patients with NVAF aged $\geq 85$ years (mostly taking vitamin $\mathrm{K}$ antagonists; mean $\mathrm{CHA}_{2} \mathrm{DS}_{2}$-VASc score 4.7) [13]. A subanalysis of an Italian registry study (START2-REGISTER) reported annual rates for ischemic stroke or systemic embolism in patients with NVAF aged $\geq 85$ years (mean $\mathrm{CHA}_{2} \mathrm{DS}_{2}$-VASc score 4.4-4.5) of 1.84 and $0.58 / 100 \mathrm{PY}$ with DOACs and warfarin, respectively [32]. A large Asian study from the Taiwan National Health Insurance database found annual rates of thromboembolic events in patients with NVAF aged $\geq 90$ years (mean $\mathrm{CHA}_{2} \mathrm{DS}_{2}$-VASc score 5.7) of 4.1 and 4.6/100 PY with DOACs and warfarin, respectively [16]. Single-center studies in Japan showed a much lower incidence rate of thromboembolic events $(0.9$ and $1.4 / 100$ PY for DOACs and warfarin, respectively, in patients with NVAF aged $\geq 80$ years [mean $\mathrm{CHADS}_{2}$ score 2.7; mean $\mathrm{CHA}_{2} \mathrm{DS}_{2}$-VASc score 5.3]) [33] and a lower incidence rate of thromboembolic events ( 0 and $1.4 \%$ per year with DOACs and warfarin, respectively) in patients with NVAF aged $\geq 90$ years (median $\mathrm{CHADS}_{2}$ score 3 ; median $\mathrm{CHA}_{2} \mathrm{DS}_{2}$-VASc score 5) [34]. Different sample sizes and sampling methods (large national database vs. single-center medical chart) may have contributed to the different incidence rates for thromboembolic events. Our study showed that the incidence rate of thromboembolism in very elderly Japanese patients with NVAF receiving OAC therapy was largely comparable to those in previous reports, although the clinical characteristics differed. In our study, half of the thromboembolic events occurred in patients receiving warfarin with a PT-INR within or above the target value. Because we could not completely rule out atherothrombotic stroke, ischemic stroke might partially include atherothrombotic stroke.

The incidence of major bleeding was high in elderly patients with NVAF. Our results show that the annual rates of major bleeding in patients with NVAF aged $\geq 85$ years were 3.1 and 4.2/100 PY with DOACs and warfarin, respectively. These incidences were comparable to those associated with OAC therapy in previous studies (ARISTOPHANES 4.9-8.5/100 PY; PREFER in AF 4.0-4.2/100 PY; START2REGISTER 2.2-2.5/100 PY; Shinohara et al. 1.5/100 PY; Yamaji et al. 2.5-5.0\%/year) [13, 17, 32-34]. Interestingly, gastrointestinal bleeding was the most common cause of major bleeding, followed by subdural hemorrhage and traumatic hemorrhage in our very elderly patients. In the DOAC 
era, the incidence of intracranial hemorrhage is decreasing, but subdural hemorrhage from falls and traumatic hemorrhage occur in this population.

The HAS-BLED score (high risk $\geq 3$ ) is a useful method for the estimation of major bleeding risk in patients with NVAF during OAC treatment $[20,35,36]$. Of the variables in a model based on a European cohort aged $\geq 65$ years, history of major bleeding and renal failure were significant risk factors for major bleeding in patients during OAC treatment [35]. In our study, a HAS-BLED score $\geq 3$ was not statistically significant among very elderly patients because approximately half of them had a score $\geq 3$. However, renal failure and history of major bleeding were independent risk factors for major bleeding, even among our very elderly patients receiving OAC treatment. Although it was not significant in our study, 9 of 22 patients who experienced major bleeding, especially gastrointestinal bleeding, received anticoagulation plus antiplatelet therapy. An observational study of elderly Japanese patients with NVAF ( $\geq 75$ years) who took apixaban (J-ELD AF Registry) reported that a history of bleeding requiring hospitalization, reduced renal function, and coadministered antiplatelets were independent factors associated with bleeding requiring hospitalization as major bleeding events [37]. These factors should be considered when prescribing OACs for elderly patients.

We found no differences in the incidence rates of thromboembolic or bleeding events between patients treated with DOACs and those treated with warfarin. Recent studies suggested a greater benefit of DOACs over warfarin in very elderly patients with NVAF because DOACs were associated with a lower risk of major bleeding [13-17, 33]. However, some studies suggested that the incidence of major bleeding was similar between elderly patients treated with DOACs and those treated with warfarin and that warfarin is still preferred over DOACs in patients aged $\geq 90$ years who have a high thromboembolic and bleeding risk [32, 34, 38]. For this population, OAC drugs should be individually considered after balancing the risks/benefits and monitoring renal function, nutritional status, activities of daily life, risk of frailty and falls, and cognitive function.

\subsection{Discontinuation of OAC Therapy}

Although OAC therapy is associated with a lower risk of thromboembolism among elderly patients, it is not known whether OAC therapy is truly useful based on balancing the risk/benefit for very elderly patients in the real-world setting. In our study, approximately $10 \%$ of patients permanently discontinued OAC therapy, with bleeding the most common reason for discontinuation. For elderly patients, major bleeding, such as gastrointestinal bleeding and intracranial hemorrhage, substantially impairs quality of life and physical activity. In particular, colonic diverticular bleeding is one of the major causes of lower gastrointestinal bleeding, and older age and anticoagulation are independent risk factors for severe diverticular bleeding $[39,40]$. In our cases, major gastrointestinal bleeding events also included colonic diverticular bleeding. Therefore, physicians worry about the use of OAC drugs, which cause serious bleeding events and prevent thromboembolism. Nonadherence and poor control of PT-INR are known to be independent risk factors for major adverse events, including major bleeding during OAC therapy [41, 42].

Another important factor is the number of comorbidities in older people. Particularly in patients with malignant diseases, life expectancy is limited, the bleeding risk from cancer is increased, and preventive treatment should be avoided at the end stage. In our study, concomitant disease status, such as malignancy and acute severe illness, was the next main reason for the discontinuation of OAC therapy. For elderly patients with a high risk of bleeding or mortality, the discontinuation of OAC therapy may be an important option to avoid impairing quality of life.

In this study, we also followed the outcomes after the discontinuation of OAC therapy. During the followup period, 12 of 33 patients died due to non-AF-related causes. Although some nonfatal strokes occurred after the discontinuation of OAC therapy, serious bleeding events did not occur.

\subsection{Death}

The J-ELD AF registry reported that the incidence of total death was 3.2/100 PY in Japanese patients with NVAF (mean age 82 years) [37]. In our study, the incidence rates of total death in patients treated with DOACs and warfarin were 2.6 and 5.3/100 PY, respectively, which was comparable to the findings of the J-ELD AF registry.

Very elderly patients with AF can have several comorbidities, including renal failure, infection, and malignancy. Therefore, cardiovascular death, in addition to stroke death or non-cardiovascular death, are expected to be common causes of death in these patients with a risk of stroke/thromboembolism. A community-based prospective survey of Japanese patients with AF (Fushimi AF registry) reported that non-cardiovascular death, mainly malignancy and infection, accounted for over half of all deaths in individuals with increasing age, and the most common cause of cardiovascular death was HF [43]. The causes of death in our study were similar to those in the Fushimi AF registry. Moreover, all deaths in patients who discontinued OAC therapy were due to non-cardiovascular causes. For very elderly patients with NVAF, the role of OAC therapy in prognosis may be limited. 


\subsection{Study Limitations}

This study has some limitations. First, the study was a retrospective observational study. For some patients, we could not exactly judge the detailed diagnosis of events by reviewing medical records. The data concerning PT-INR and other clinical parameters at the time of thromboembolic and major bleeding events were not available in all cases. Additionally, treatment selection bias existed. In this study, only onequarter were new OAC users, most of whom were introduced to DOACs, and the remainder were prevalent users, of whom two-thirds continued warfarin. A methodologic concern for this study was that the event rates during the OAC-exposed person-time before 85 years of age among these prevalent users were not ascertained. There was a bias in prescribing OAC drugs for these very elderly patients, and our findings might include this heterogeneity. However, a stratified analysis was not feasible because of the small sample size. Second, this was a single-center cohort study. The clinical characteristics of our patients might not reflect those of general patients with NVAF in Japan because our institution is a university hospital. Third, we did not assess physical activity, frailty, or cognitive status for all patients. These variables are known to be related to outcomes in elderly patients, but we could not evaluate their impacts on OAC-related outcomes in this study. Fourth, the number of subjects was small, so subgroup analysis was not feasible. We could not make conclusions regarding the superiority of either DOACs or warfarin in terms of efficacy and safety because of the limited ability of this study design to avoid confounders and bias.

\section{Conclusions}

Our results revealed that, in patients with NVAF aged $\geq$ 85 years, the incidence of thromboembolism and major bleeding was similar with DOACs and warfarin and that gastrointestinal bleeding and subdural hemorrhage were common causes of major bleeding. During the follow-up, approximately $10 \%$ of patients permanently discontinued OAC therapy, with bleeding events and concomitant diseases, including malignancies and acute illnesses, being the most common reasons for discontinuation.

\section{Declarations}

Funding This research received no grants from any funding agency in the public, commercial, or not-for-profit sectors.

Conflicts of Interest/Competing interests T.S and N.H received research funding from Daiichi-Sankyo and received lecture fees from Daiichi-Sankyo and Bristol-Myers Squibb. M. N has nothing to disclose.
Ethics Approval The protocol was approved by the Institutional Review Board of Tokyo Women's Medical University (2887-R2) in view of the retrospective nature of the study, and all the procedures performed were part of routine care.

Consent to Participate The requirement for written informed consent was waived because of the retrospective design.

Consent for Publication Not applicable.

Availability of Data and Materials The data that support the findings of this study are available from the corresponding author upon reasonable request.

Code Availability Not applicable.

Author Contributions M.N and T.S conceived and designed the study. M.N collected and organized the patient data from the patient files. M.N and T.S analyzed the data. N.H contributed to the interpretation of the data. T.S was a major contributor in writing the manuscript. All authors read and approved the final manuscript.

Informed Consent The requirement for written informed consent was waived because of the retrospective design.

Open Access This article is licensed under a Creative Commons Attribution-NonCommercial 4.0 International License, which permits any non-commercial use, sharing, adaptation, distribution and reproduction in any medium or format, as long as you give appropriate credit to the original author(s) and the source, provide a link to the Creative Commons licence, and indicate if changes were made. The images or other third party material in this article are included in the article's Creative Commons licence, unless indicated otherwise in a credit line to the material. If material is not included in the article's Creative Commons licence and your intended use is not permitted by statutory regulation or exceeds the permitted use, you will need to obtain permission directly from the copyright holder. To view a copy of this licence, visit http://creativecommons.org/licenses/by-nc/4.0/.

\section{References}

1. Feinberg WM, Blackshear JL, Laupacis A, Kronmal R, Hart RG. Prevalence, age distribution, and gender of patients with atrial fibrillation. Analysis and implications. Arch Intern Med. 1995;155:469-73.

2. Go AS, Hylek EM, Phillips KA, Chang Y, Henault LE, Selby JV, Singer DE. Prevalence of diagnosed atrial fibrillation in adults: national implications for rhythm management and stroke prevention: the AnTicoagulation and Risk Factors in Atrial Fibrillation (ATRIA) study. JAMA. 2001;285:2370-5.

3. Chugh SS, Havmoeller R, Narayanan K, Singh D, Rienstra M, Benjamin EJ, Gillum RF, Kim YH, McAnulty JH Jr, Zheng ZJ, Forouzanfar MH, Naghavi M, Mensah GA, Ezzati M, Murray CJ. Worldwide epidemiology of atrial fibrillation: a global burden of disease 2010 study. Circulation. 2014;129:837-47.

4. Wolf PA, Abbott RD, Kannel WB. Atrial fibrillation as an independent risk factor for stroke: the Framingham Heart Study. Stroke. 1991;22:983-8.

5. Thrall G, Lane D, Carroll D, Lip GY. Quality of life in patients with atrial fibrillation: a systematic review. Am J Med. 2006;119(448):e1-.

6. Lloyd-Jones DM, Wang TJ, Leip EP, Larson MG, Levy D, Vasan RS, D'Agostino RB, Massaro JM, Beiser A, Wolf PA, 
Benjamin EJ. Lifetime risk for development of atrial fibrillation: the Framingham Heart Study. Circulation. 2004;110:1042-6.

7. Hughes M, Lip GY. Stroke and thromboembolism in atrial fibrillation: a systematic review of stroke risk factors, risk stratification schema and cost effectiveness data. Thromb Haemost. 2008;99:295-304.

8. Stroke in Atrial Fibrillation Working Group. Independent predictors of stroke in patients with atrial fibrillation: a systematic review. Neurology. 2007;69:546-54.

9. Marinigh R, Lip GYH, Fiotti N, Giansante C, Lane DA. Age as a risk factor for stroke in atrial fibrillation patients. J Am Coll Cardiol. 2010;56:827-37.

10. Andreotti F, Rocca B, Husted S, Ajjan RA, Berg J, Cattaneo M, Collet JP, De Caterina R, Fox KAA, Halvorsen S, Huber K, Hylek EM, Lip GYH, Montalescot G, Morais J, Patrono C, Verheugt FWA, Wallentin L, Weiss TW, Storey RF, on behalf of the ESC Thrombosis Working Group. Antithrombotic therapy in the elderly: expert position paper of the European Society of Cardiology Working Group on Thrombosis. Eur Heart J. 2015;36:3238-49.

11. Mant J, Hobbs FDR, Fletcher K, Roalfe A, Fitzmaurice D, Lip GY, Murray E, on behalf of the BAFTA investigators, and the Midland Research Practices Network (MidReC). Warfarin versus aspirin for stroke prevention in an elderly community population with atrial fibrillation (the Birmingham Atrial Fibrillation Treatment of the Aged Study, BAFTA): a randomised controlled trial. Lancet. 2007;370:493-503.

12. Singer DE, Chang Y, Fang MC, Borowsky LH, Pomernacki NK, Udaltsova N, Go AS. The net clinical benefit of warfarin anticoagulation in atrial fibrillation. Ann Intern Med. 2009;151:297-305.

13. Patti G, Lucerna M, Pecen L, Siller-Matula JM, Cavallari I, Kirchhof P, De Caterina R. Thromboembolic risk, bleeding outcomes and effect of different antithrombotic strategies in very elderly patients with atrial fibrillation: A sub-analysis from the PREFER in $\mathrm{AF}$ (prevention of thromboembolic events-European registry in atrial fibrillation). J Am Heart Assoc. 2017;6:e005657. https:// doi.org/10.1161/JAHA.117.005657.

14. Halvorsen S, Atar D, Yang H, De Caterina R, Erol C, Garcia D, Granger CB, Hanna M, Held C, Husted S, Hylek EM, Jansky P, Lopes RD, Ruzyllo W, Thomas L, Wallentin L. Efficacy and safety of apixaban compared with warfarin according to age for stroke prevention in atrial fibrillation: observations from the ARISTOTLE trial. Eur Heart J. 2014;35:1864-72.

15. Kato ET, Giugliano RP, Ruff CT, Koretsune Y, Yamashita T, Kiss RG, Nordio F, Murphy SA, Kimura T, Jin J, Lanz H, Mercuri M, Braunwald E, Antman EM. Efficacy and safety of edoxaban in elderly patients with atrial fibrillation in the ENGAGE AFTIMI 48 trial. J Am Heart Assoc. 2016;5:e003432. https://doi. org/10.1161/JAHA.116.003432.

16. Chao TF, Liu CJ, Lin YJ, Chang SL, Lo LW, Hu YF, Tuan TC, Liao JN, Chung FP, Chen TJ, Lip GYH, Chen SA. Oral anticoagulation in very elderly patients with atrial fibrillation: a nationwide cohort study. Circulation. 2018;138:37-47.

17. Deitelzweig S, Keshishian A, Li X, Kang A, Dhamane AD, Luo X, Balachander N, Rosenblatt L, Mardekian J, Pan X, Nadkarni A, Di Fusco M, Garcia Reeves AB, Yuce H, Lip GYH. Comparisons between oral anticoagulants among older nonvalvular atrial fibrillation patients. J Am Geriatr Soc. 2019;67:1662-711.

18. Shen AY-J, Yao JF, Brar SS, Jorgensen MB, Chen W. Racial/ethnic differences in the risk of intracranial hemorrhage among patients with atrial fibrillation. J Am Coll Cardiol. 2007;50:309-15.

19. Klatsky AL, Friedman GD, Sidney S, Kipp H, Kubo A, Armstrong MA. Risk of hemorrhagic stroke in Asian American ethnic groups. Neuroepidemiology. 2005;25:26-31.
20. van Walraven C, Hart RG, Connolly S, Austin PC, Mant J, Hobbs FD, Koudstaal PJ, Petersen P, Perez-Gomez F, Knottnerus JA, Boode B, Ezekowitz MD, Singer DE. Effect of age on stroke prevention therapy in patients with atrial fibrillation: the atrial fibrillation investigators. Stroke. 2009;40:1410-6.

21. Poli D, Antonucci E, Grifoni E, Abbate R, Gensini GF, Prisco D. Bleeding risk during anticoagulation in atrial fibrillation patients older than 80 years. J Am Coll Cardiol. 2009;54:999-1002.

22. JCS Joint Working Group. Guidelines for pharmacotherapy of atrial fibrillation (JCS 2013)-digest version. Circ J. 2014;78:1997-2021.

23. Cockcroft DW, Gault MH. Prediction of creatinine clearance from serum creatinine. Nephron. 1976;16:31-41.

24. Hunt SA, Abraham WT, Chin MH, et al. 2009 Focused update incorporated into the ACC/AHA 2005 guidelines for the diagnosis and management of heart failure in adults: a report of the American College of Cardiology Foundation/American Heart Association Task Force on Practice Guidelines. Circulation. 2009;119:e391-479.

25. Camm AJ, Kirchhof P, Lip GY, Schotten U, Savelieva I, Ernst S, Van Gelder IC, Al-Attar N, Hindricks G, Prendergast B, Heidbuchel H, Alfieri O, Angelini A, Atar D, Colonna P, De Caterina R, De Sutter J, Goette A, Gorenek B, Heldal M, Hohloser SH, Kolh P, Le Heuzey JY, Ponikowski P, Rutten FH, ESC Committee for Practice Guidelines, Vahanian A, Auricchio A, Bax J, Ceconi C, Dean V, Filippatos G, Funck-Brentano C, Hobbs R, Kearney P, McDonagh T, Popescu BA, Reiner Z, Sechtem U, Sirnes PA, Tendera M, Vardas PE. Guidelines for the management of atrial fibrillation: the Task Force for the Management of Atrial Fibrillation of the European Society of Cardiology (ESC). Eur Heart J. 2010;31:2369-429.

26. Rosendaal FR, Cannegieter SC, van der Meer FJ, Briët E. A method to determine the optimal intensity of oral anticoagulant therapy. Thromb Haemost. 1993;69:236-9.

27. Fine JP, Gray RJ. A proportional hazards model for the subdistribution of a competing risk. J Am Stat Assoc. 1999;94:496-509.

28. Kanda Y. Investigation of the freely available easy-to-use software 'EZR' for medical statistics. Bone Marrow Transplant. 2013;48:452-8.

29. Hiasa KI, Kaku H, Inoue H, Yamashita T, Akao M, Atarashi H, Koretsune Y, Okumura K, Shimizu W, Ikeda T, Toyoda K, Hirayama A, Yasaka M, Yamaguchi T, Teramukai S, Kimura T, Kaburagi J, Takita A, Tsutsui H. Age-related differences in the clinical characteristics and treatment of elderly patients with atrial fibrillation in Japan - insight from the ANAFIE (All Nippon AF In Elderly) Registry. Circ J. 2020;84:388-96.

30. Okumura Y, Yokoyama K, Matsumoto N, Tachibana E, Kuronuma K, Oiwa K, Matsumoto M, Kojima T, Hanada S, Nomoto K, Arima K, Takahashi F, Kotani T, Ikeya Y, Fukushima S, Itoh S, Kondo K, Chiku M, Ohno Y, Onikura M, Hirayama A, The Sakura AF Registry Investigators. Current use of direct oral anticoagulants for atrial fibrillation in Japan: findings from the SAKURA AF Registry. J Arrhythm. 2017;33:289-96.

31. Masunaga N, Abe M, Ogawa H, Aono Y, Ikeda S, Doi K, An Y, Ishii M, Iguchi M, Esato M, Tsuji H, Wada H, Hasegawa K, Lip GYH, Akao M, Fushimi AF Registry Investigators. Current status, time trends and outcomes of combination therapy with oral anticoagulant and antiplatelet drug in patients with atrial fibrillation-The Fushimi AF Registry. Circ J. 2018;82:2983-91.

32. Poli D, Antonucci E, Ageno W, Bertù L, Migliaccio L, Martinese L, Pilato G, Testa S, Palareti G. Oral anticoagulation in very elderly patients with atrial fibrillation: results from the prospective multicenter START2-REGISTER study. PLoS ONE. 2019;14:e0216831. https://doi.org/10.1371/journal.pone.0216831.

33. Shinohara M, Wada R, Yao S, Yano K, Akitsu K, Koike H, Kinoshita T, Yuzawa H, Suzuki T, Fujino T, Ikeda T. Evaluation 
of oral anticoagulants in atrial fibrillation patients over 80 years of age with nonsevere frailty. J Arrhythm. 2019;35:795-803.

34. Yamaji H, Higashiya S, Murakami T, Hina K, Kawamura H, Murakami M, Kamikawa S, Hirohata S, Kusachi S. Effects of oral anticoagulants on patients with atrial fibrillation aged 90 years and older: comparison among direct oral anticoagulant, warfarin anticoagulant, and nonanticoagulation. J Cardiovasc Pharmacol. 2019;74:246-54.

35. Pisters R, Lane DA, Nieuwlaat R, de Vos CB, Crijns HJ, Lip GY. A novel user-friendly score (HAS-BLED) to assess 1-year risk of major bleeding in patients with atrial fibrillation: the Euro Heart Survey. Chest. 2010;138:1093-100.

36. Apostolakis S, Lane DA, Guo Y, Buller H, Lip GY. Performance of the HEMORR(2)HAGES, ATRIA, and HAS-BLED bleeding risk-prediction scores in patients with atrial fibrillation undergoing anticoagulation: the AMADEUS (evaluating the use of SR34006 compared to warfarin or acenocoumarol in patients with atrial fibrillation) study. J Am Coll Cardiol. 2012;60:861-7.

37. Okumura K, Yamashita T, Suzuki S, Akao M, on behalf of J-ELD AF Investigators. A multicenter prospective cohort study to investigate the effectiveness and safety of apixaban in Japanese elderly atrial fibrillation patients (J-ELD AF Registry). Clin Cardiol. 2020;43:251-9.
38. Ehrlinder H, Orsini N, Modig K, Hofman-Bang C, Wallén H, Gigante B. Clinical characteristics and antithrombotic prescription in elderly hospitalized atrial fibrillation patients: a crosssectional analysis of a Swedish single-center clinical cohort. Int J Cardiol Heart Vasc. 2020;27:100505. https://doi.org/10.1016/j. ijcha.2020.100505.

39. Lewis M. Bleeding colonic diverticula. J Clin Gastroenterol. 2008;42:1156-8.

40. Joaquim N, Caldeira P, Antunes AG, Eusébio M, Guerreiro H. Risk factors for severity and recurrence of colonic diverticular bleeding. Rev Esp Enferm Dig. 2017;109:3-9.

41. Salmasi S, Loewen PS, Tandun R, Andrade JG, De Vera MA. Adherence to oral anticoagulants among patients with atrial fibrillation: a systematic review and meta-analysis of observational studies. BMJ Open. 2020;10:e034778.

42. Björck F, Renlund H, Lip GY, Wester P, Svensson PJ, Själander A. Outcomes in a warfarin-treated population with atrial fibrillation. JAMA Cardiol. 2016;1:172-80.

43. An Y, Ogawa H, Yamashita Y, Ishii M, Iguchi M, Masunaga N, Esato M, Tsuji H, Wada H, Hasegawa K, Abe M, Lip GYH, Akao M. Causes of death in Japanese patients with atrial fibrillation: The Fushimi Atrial Fibrillation Registry. Eur Heart J Qual Care Clin Outcomes. 2019;5:35-42. 